Studia Anglica Posnaniensia 46/3, 2011(2010)

doi: 10.2478/v10121-010-0005-6

\title{
ERROR-BASED EVIDENCE FOR INTERFERENCE FROM POLISH GLIDING RULES ON ENGLISH PRONUNCIATION
}

\author{
HANNA DZICZEK-KARLIKOWSKA
}

Academy of Management, Warsaw

\begin{abstract}
This paper examines pronunciation errors made by Polish learners of English. The focus is on the phonology of glides in Polish and English. The purpose of the presented evaluation of errors is to demonstrate that phonological interference finds its source in the phonological rules of the native language having no correspondents in the target language or in the differences in the treatment of diphthongs by both languages.
\end{abstract}

\section{Introduction}

In the analysis of pronunciation errors addressed in this paper, I attempt to show the relatedness between the phonological systems of Polish and English. To handle the problem, I adopt the theoretical frameworks of Standard Generative Phonology (Chomsky - Halle 1968) and Optimality Theory (Prince - Smolensky 1993). The analyses run simultaneously in both frameworks aim to state generalizations and make predictions. The rule-based phonology, where the intricacies of gliding are resolved by the application of the fully productive rules, gives a coherent analysis of the investigated body of data. Similarly, the constraint-based phonology, where the solution is offered by the system of universal constraints, successfully accounts for the examined phenomena. However, for the generalizations concerning the insertion of the back glide, standard Optimality Theory does not produce a straightforward account. This study proves that the introduction of a two-level evaluation, as envisaged by Derivational Optimality Theory (DOT, hereafter), satisfactorily handles the ongoing changes. This modified version of OT is provided, among others, by Kiparsky $(1997,2000)$ and Rubach $(1997,2000,2003)$. 
The theoretical information provided in the ensuing sections is interspersed with some descriptive data from Polish and English. These include the inventories of consonants and vowels. The data are generally considered well-known and uncontroversial in the scope of English and Polish phonology that is relevant for the purposes of the analyses presented in this paper. They have been drawn from standard sources such as Reszkiewicz (1984), Rubach (1984a), Gimson (2001), Wells (2000) and Ladefoged (1993).

\section{Overview of pronunciation errors}

It is generally considered that English diphthongs are problematic for Polish learners of English due to phonetic differences between both languages and due to the differences in the affiliation of the discussed segments within the syllable. The comparison of the phonetic differences between the corresponding segments of English diphthongs and Polish vowel/glide sequences lead to the conclusion that the closing diphthongs are mispronounced by Poles with the following vowel/glide sequences: [er] as in age, playing $\rightarrow$ [ej] as in wejść 'get in', [ar] as in time, notifying $\rightarrow$ [aj] as in maj 'May', [I] as in coin, boyish $\rightarrow$ [0j] as in wojna 'war', [av] as in now, allowing $\rightarrow$ [aw] as in Maurycy 'Maurice', [əv] as in go, rowing $\rightarrow[\mathrm{ow}]$ as in koldra 'duvet'.

The second element of the diphthongs [er], [ar] and [or] is different from the Polish [i] and [j]. Namely, in the English diphthongal glides, the transition from [a], [e], [0] to [I] is gradual and slow. During the gliding movement from the starting point to the target element, the tongue stops about half-way without reaching the position of the front [I]. In actuality, the target reached by these diphthongs is approximately between [ə] and [I]. Such reductions in the closing movement of the tongue cause difficulty to Polish learners since the Polish glide is fully realized, i.e. the tongue reaches the position of [j]. Therefore, it appears that, in purely phonetic terms, interference from Polish may come from insufficient suppression of the tongue closing movement. Referring to [av] and [əo], the target point [ $\mathrm{v}]$ is lower and more central, with weaker lip-rounding than Polish $[\mathrm{u}]$. In the speech of Poles, the sound surfaces as the fully realized back glide [w], which is higher than English [ $\mathrm{v}$. Therefore, the difficulty that Poles have in the pronunciation of these diphthongs is, as in the case of [er], [ar] and [or], a consequence of insufficient suppression of the closing tongue movement and the degree of lip-rounding, which are typical of the Polish articulation of [w].

With regard to the centring diphthongs /ra/, /va/ and /ea/, among others, Sobkowiak (2001) claims that one of the reasons why Poles mispronounce them is the target position, i.e. /a/, which is mid-central in English while Polish does not use any sound produced in this position. Additionally, Polish learners start the gliding movement of the tongue at positions typical for Polish $/ \mathrm{i} /, / \varepsilon /$ and $/ \mathrm{u} /$ 
whereas in English, the starting positions are more centralized due to the context of the following schwa. Another articulatory problem for Poles is caused by the fact that Polish does not accept two vocalic qualities within one syllable. In order to break the hiatus of two vowels, Poles use an intervening glide, as in, for instance, trio [tri.jo] 'trio' and aktualny [tu.wa] 'current'. '

Given that Polish learners transfer the Polish spreading processes into English, the English centring diphthongs /Iə/ and / $\mathrm{va/}$, as in fierce [fiəs] and poor [puə] will be incorrectly pronounced as [ije] and [uwe], that is, with the same sequences which appear in the Polish words pije 'is drinking' and butek 'buns'(gen.pl.). However, if the /rə/ diphthong occurs in unstressed syllables, as in monomorphemic area or regularly graded i-final adjectives, for example, happier and happiest, Polish learners show a tendency to glide [i] to [j]. ${ }^{2}$

Before presenting an account for the phonological mechanisms causing the errors, let us look at the differences between the English diphthongs and the Polish vowel/glide sequences and at the basic concepts relating to the syllable and syllabification.

\section{Vowel-glide relation and syllabification mechanisms}

The high vowels [i] and [u] and the respective glides [j] and [w] are similar with regard to the way in which they are articulated. This phonetic similarity leads to the conclusion that high vowels and the corresponding glides have the same melodic structure. Thus, both [i] and [j] are [+high], [-back] and [-cons], whereas $[\mathrm{u}]$ and $[\mathrm{w}]$ are $[+$ high $],[+$ back $]$ and [-cons]. Another feature characteristic of both high vowels and glides is their occurrence in complementary distribution, where vowels appear before consonants while glides before vowels. Phonetic similarities and complementary distribution point to the fact that the high vowels are in the underlying representation and the glides are derived by rules. Furthermore, the difference between high vowels and glides resides in their affiliation within the syllable. The former erect syllable peaks, whereas the latter are placed in non-peak positions.

In moraic representation (Hock 1986; McCarthy - Prince 1986; Hayes 1989) assumed throughout this study, a vowel [i] is represented as a melodic unit linked to a mora (marked as $\mu$ ), while a glide is associated either with the onset (1b) or with the coda (1c), as shown below.

\footnotetext{
1 Note that the hiatus of two vowels can be split by inserting either a glide or a glottal stop. However, in Polish, when one of the vowels is high, the glide is preferred (Rubach 2000; Dziczek-Karlikowska 2007).

2 For more details, see Sobkowiak (2001).
} 
(1)

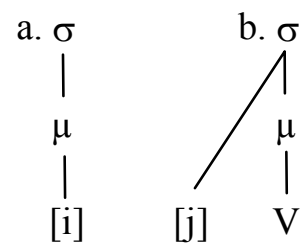

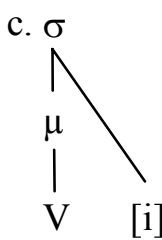

syllable tier

melodic tier

The pattern of the vowel-glide relation outlined above predicts the occurrence of the glide [j] in a prevocalic position, as in the English word yet [jet]. If a consonant follows, the melodic [i] is attached to the syllable peak, as in, for example, enough [In $\Lambda \mathrm{f}]$.

This predictability is accounted for on the assumption that glides derive from underlying vowels. Then, gliding consists in the deletion of a mora. For instance, the word yet [jet] comes from the underlying//iet// which, according to the syllabification rules, contains two onsetless syllables, i.e. [i.et]. From the assumption that vowel initial syllables are more marked than syllables that have onsets, it follows that $i$ syllabified into the onset becomes a glide, creating a well-formed syllable, i.e. the monosyllabic [jet].

A different view from that given by Standard Generative Phonology regarding the relation between high vowels and glides is offered by Optimality Theory. In OT, the processes of gliding and glide insertion follow from the interaction of faithfulness constraints and well-formedness constraints as defined by Prince and Smolensky (1993) and McCarthy and Prince (1995). As is generally known, in terms of typology, certain syllable types are preferred over other types and there is a cross-linguistic preference for syllables with onsets, i.e. beginning with a consonant or a glide. This is expressed by the markedness constraint ONSET (Syllables must have onsets. This constraint is satisfied only if a syllable has an onset (a consonant or a glide). Thus, languages in which ONSET is undominated have obligatory onsets. In words such as yet [jet], gliding is used as a strategy to satisfy ONSET: //iet// $\rightarrow$ [jet]. In the rule-based phonology, the process of gliding consists in the deletion of an underlying mora. In the constraint-based phonology, all the modifications of the input, i.e. changes to an underlying representation, are prohibited by the faithfulness constraints (Prince - Smolensky 1993; McCarthy - Prince 1994, 1995). Faithfulness constraints evaluate the relationship between the input and the output.

Since [jet] is preferred to [i.et], it is better to delete a mora (syllabify $/ / \mathrm{i} / /$ into the onset) than to have an onsetless syllable. Therefore ONSET is ranked above $\operatorname{MAX}_{\mu}$ (Every mora of the input has a correspondent in the output.) The tableau in (2) illustrates this ranking. ${ }^{3}$

3 The winning candidate is always listed first and is indicated with an arrow. The undesired candidate that wins in the evaluation is always indicated with an arrow of opposite direc- 


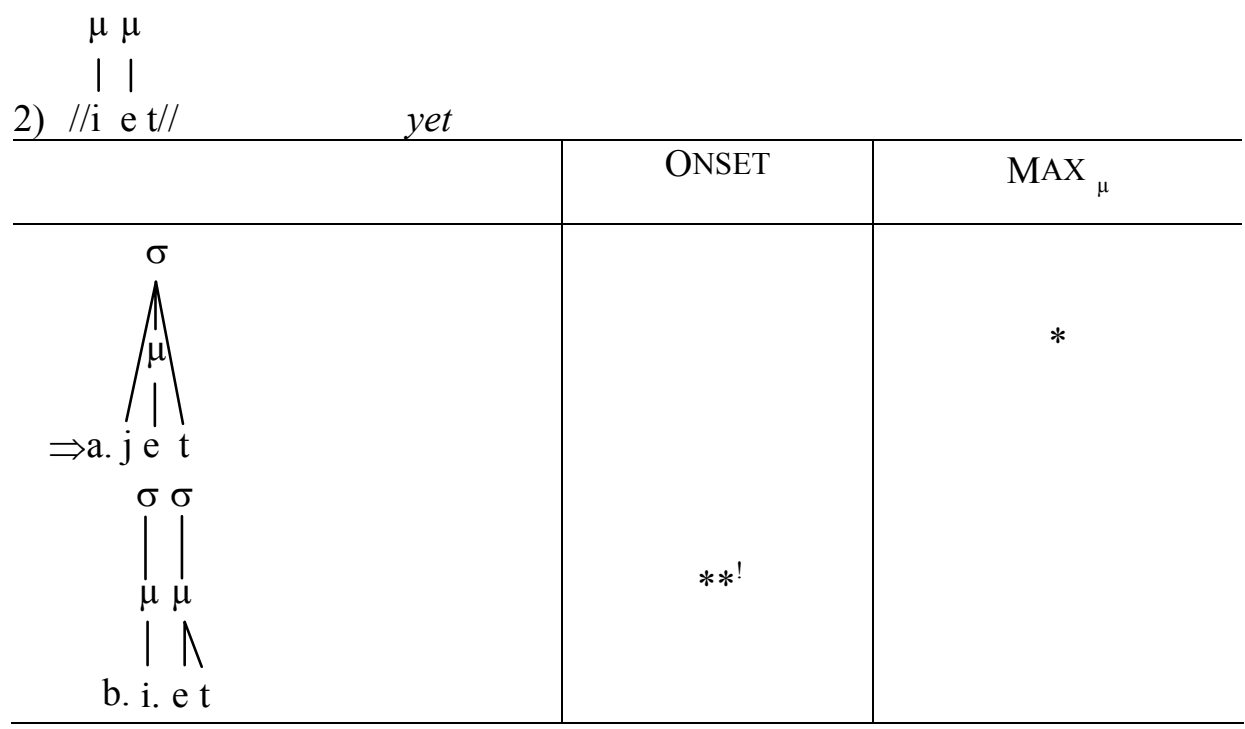

The effect of this ranking is that the optimal candidate (2a) violates the lowerranked $\operatorname{MAX} \mu$ but still it is a better candidate than $(2 b)$, which violates the undominated ONSET twice.

It needs to be mentioned that ONSET is a violable constraint in English. This is shown by words such as enough that begin with a vowel and, hence, do not comply with ONSET. One way to solve the problem of an onsetless syllable is to delete a vowel. However, this solution is not used in English, which means that MAX $_{\text {Seg }}$ (Do not delete a segment) dominates ONSET. ${ }^{4}$

Another strategy to avoid onsetless syllables is an insertion of a segment. In such a case, however, instead of the correct, e.g. impatient [Im'perJent], we

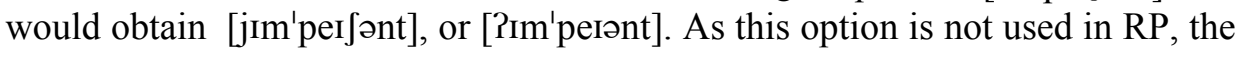
conclusion is that ONSET is outranked by $\mathrm{DEP}_{\text {Seg }}$ (Do not insert a segment).

\section{Reanalysis of diphthongs}

Diphthongs in traditional grammars and in generative phonology are completely different concepts. In traditional grammars, diphthongs are defined phonetically only. For instance, for Gimson (2001), the diphthong is a sequence of two vocalic elements forming a glide within one syllable. The RP diphthongs have their first element sounds in the general region of [I, e, a, ə, v] and for their sec-

tion. An exclamation mark denotes the candidate that has been eliminated from further evaluation.

4 There are languages that use elision to resolve hiatus; for details, see Casali $(1996,1997)$. 
ond element $[\mathrm{I}, \partial, \mho]$.When prominence is concentrated on the first element, the diphthong is said to be falling. When prominence is on the second element, the diphthong is described as a rising type. The diphthongal glides with prominent first element are the following: [eI] as in pay, [aI] as in pie, [əI] as in coy, [əu] as in bow (archery), [av] as in bough, [1ə] as in peer, [eə] as in pair, [və] as in poor. The sequences [I] $+[\vartheta]$ and $[\mho]+[ə]$, in unaccented syllables, have the first elements weaker than the second ones. In such cases, $[\mathrm{I}]$ and $[\mathrm{v}]$ are weakening to the semi-vowels [j] and [ $\mathrm{v}$, respectively, giving rising diphthongs. Thus in windier and influence, the diphthongs are of a rising type. ${ }^{5}$

Generative grammars use phonological behavior as evidence for the existence of diphthongs. To exemplify the point, the sequences /eI, aI, oI, au, əu/ from the phonetic point of view, are classified as closing diphthongs with falling sonority. From the phonological point of view, such combinations may be interpreted in two different ways. In the moraic theory (Hayes 1989), both elements of a diphthong carry moras that constitute a syllable peak, as in (3a). If there is a sequence of a vowel and a glide, the representation is as in (3b).

3) a.

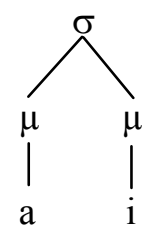

b.

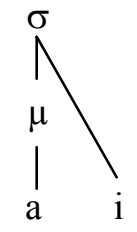

While (3a) is a typical representation of the English diphthong, the configuration in ( $3 b$ ) is typical of the Polish vowel plus glide string. In order to establish the phonological status of the second member of the English diphthong, let us observe how it behaves with respect to syllabification rules. In English, when the suffix -ing is added to a stem, both members of a diphthong remain syllabified in the same syllable, as shown in annoy [ə.nэг] $\rightarrow$ annoy+ing [ə.nə..I]], say [ser] $\rightarrow$ say+ing [seI.II], try [traI] $\rightarrow$ try+ing [traI.In].

The syllabification is different in Polish, where the glide is resyllabified to the onset of the following syllable, as shown by raj [raj] 'paradise' $\rightarrow r a j+u$ [ra.ju] 'paradise' (gen.sg.) and bajka [baj.ka] 'fairy tale' $\rightarrow$ baj+ek [ba.jek] 'fairy tale' (gen.pl.).

5 There is no agreement among phoneticians as to the definition of a diphthong. For instance, Wells (2000) regards diphthongs as sequences of two vowel qualities within a single syllable. According to Wells, [je] in yes is a rising diphthong. Jassem (1971) regards diphthongs as sequences of vowels and glides. Still another view is represented by Ladefoged (1993), for whom a diphthong means a movement from one vowel to another within a single syllable. 
In annoying, saying and trying, the second member in the sequence is syllabified together with the first member. This means that [I] belongs to the syllable nucleus, so it cannot resyllabify to the onset of the following syllable: *[se.jin]. In contrast, the Polish $j$ in words such as bajka 'fairy tale' always resyllabifies into $i \mathrm{~V}$ sequences, creating an onset, as in bajek [ba.jek] 'fairy tales' (gen.pl.). Therefore, the syllabification of the constituents in given sequences shows that we are dealing with true diphthongs in English and vowel plus glide sequences in Polish.

Recapitulating the points made above, the errors made by English-speaking Poles in native English closing diphthongs show that instead of the second element of the English diphthong a vocalic offglide is produced. For instance, the hypothesized pronunciation of [I] in [er], [ar], [ $\mathrm{r}]$ as in say, try, annoy, respectively, is [j]. The phonetic facts suggest that this type of error can be due to the fact that Polish does not have true diphthongs. Phonologically, this means that the structure of the English diphthong given in (3a) has been reanalysed by Poles as the structure in which the second element is linked to the syllable node (3b) and hence is a coda, which is typical of Polish.

In terms of OT, such errors may be explained by the postulation of the No Diphthong (NODIPH) constraint penalizing a configuration in which two tautosyllabic moras are linked to two separate vocalic nodes at the melodic tier (Rosenthall 1994). The constraint is formulated in (4).

4) NODIPH

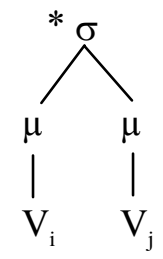

Following Rosenthall (1994) and Rubach (2000), the presence or absence of diphthongs in a given language is easily explained by assuming different rankings of NODIPH. As diphthongs occur in English, NODIPH must be a low-ranked constraint. Further, as there are English words such as age, time, annoy, etc., where the underlying representation containing two vowels surfaces as a diphthong, it is assumed that NODIPH is outranked by $\mathrm{MAX}_{\mu}$. Therefore, in, for instance, say //sei// $\rightarrow$ [seI], such ranking will prevent the detachment of the mora from $/ / \mathbf{i} / /$ and will form a diphthong on the surface. This is demonstrated by the tableau in (5). 


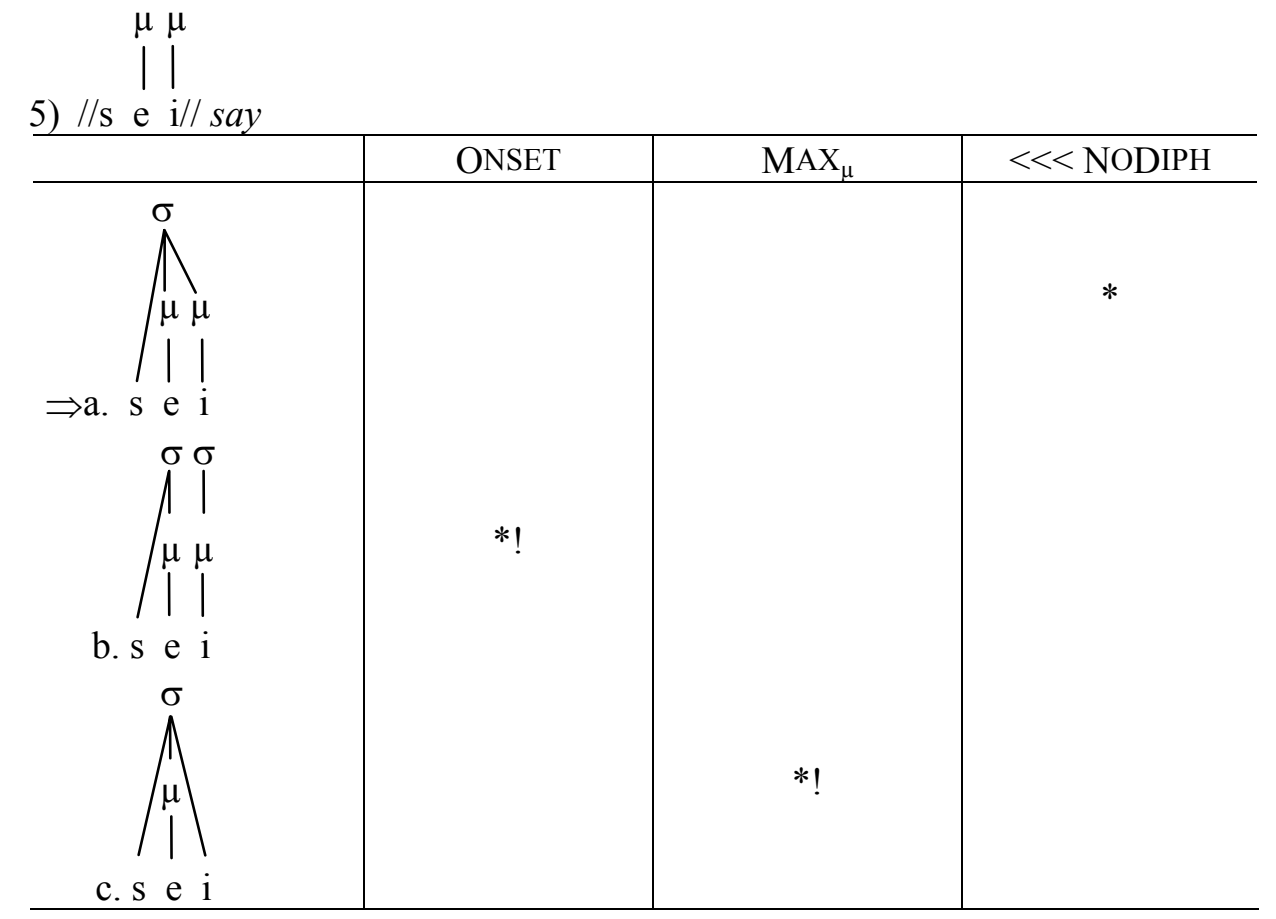

Candidate (5b) has an onsetless syllable and, hence, is ruled out from the evaluation by the high-ranked ONSET. Candidate (5c) syllabifies $i$ into the coda, which incurs a fatal violation of $\operatorname{MAX} \mu$. In candidate (5a), the melodic $e$ and $i$ preserve the underlying moras linking them directly to the syllable node. This incurs a violation of NODIPH but, still, candidate (5a) comes out as optimal since NODIPH is ranked low in English.

As shown in (6a) below, a coda is created by gliding the high vowel. As is well-known, codas are disfavoured cross-linguistically. In OT, this generalization is expressed by the *CODA constraint, mandating that syllables cannot have codas. As $i$ glides in words such as bajka 'fairy tale', it is concluded that ONSET outranks *CODA. The respective ranking is illustrated in (6), where the relevant portion of the word bajka 'fairy tale' is evaluated. 


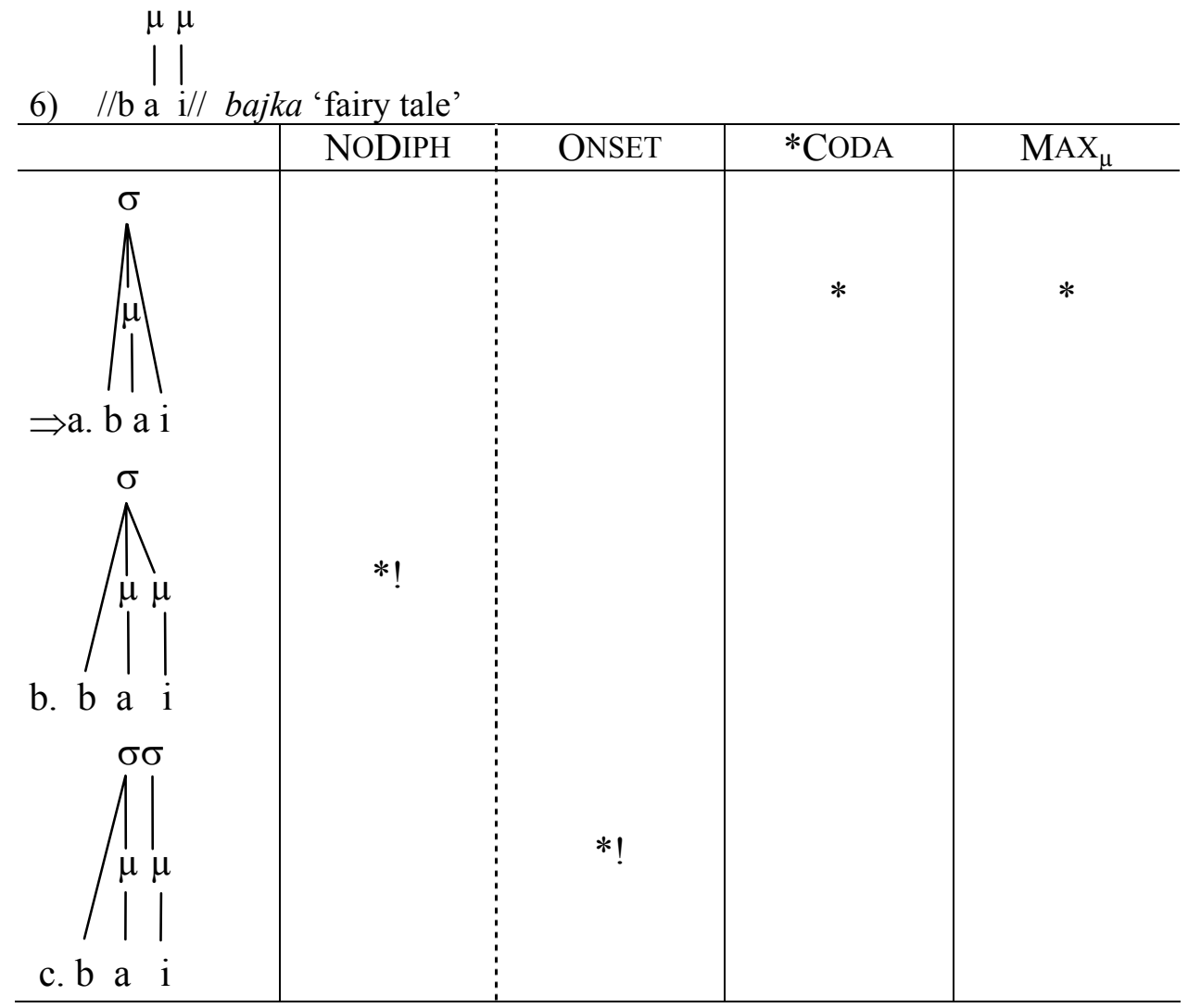

Candidate (6b) loses in this evaluation, as it violates the undominated NODIPH, whereas (6c), having an onsetless syllable, is excluded by the high-ranked ONSET. Candidate (6a) fares better than its contenders even if it violates the two lowranked ${ }^{*} \mathrm{CODA}$ and $\mathrm{MAX}_{\mu}$ constraints. Therefore, the above evaluation shows that it is better to glide the high vowel than to syllabify $i$ into the syllable peak.

\section{Glide Insertion}

From the point of view of Standard Generative Phonology, the mispronunciation of fierce [fiəs] as [fijes] can be due to Glide Insertion. Note that, similarly to the Polish word trio [tri.jo], the high vowel /i/ in fierce does not glide but spawns a glide. The features of the high vowel are copied to a glide by spreading. Like in trio 'trio', gliding is blocked because $i$ is prespecified for the syllable node. It seems that to obtain the surface fierce [fres], it is enough to leave $i$ without the prespecification for the syllable node. However, if $i$ were not prespecified, Poles would glide it, while in English, a sequence of two vocalic elements surfaces as a diphthong. 
With regard to the back glide insertion in poor [puə], mispronounced as [puwe], the rule of Glide Insertion copies the features of the high vowel /u/. As in the case of $j$-Insertion, an empty Root node is added, as glides cannot share the Root node with the vowels that spawn them. Unlike in the case of fierce, in poor the high vowel $u$ does not have to be prespecified because there is no danger of gliding. It follows from the fact that Polish has a rule $\mathrm{i} \rightarrow \mathrm{j} /-\mathrm{V}$ but not $\mathrm{u} \rightarrow \mathrm{w} /-\mathrm{V}$.

From the point of view of Optimality Theory, the problem of glide insertion and gliding is explained in terms of the different ranking of constraints. The ranking of constraints that ensures the correct surface [ə] in English words is as follows: ONSET, $\mathrm{MAX}_{\mu},{ }^{*} \mathrm{COMPLEX}_{\text {Onset }}>>$ NODIPH, where ${ }^{*} \mathrm{COMPLEX}_{\text {Onset }}$ does not permit complex onsets. ${ }^{6}$ The evaluation of the word fierce [fres] discussed above is as in (7).

$\mu \mu$

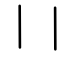

7) $/ / \mathrm{f}$ i $\mathrm{a} / /$ fierce $[\mathrm{fr}$ ]

\begin{tabular}{|c|c|c|c|c|}
\hline & ONSET & $\mathrm{MAX}_{\mu}$ & ${ }^{*}$ COMPLEX $_{\text {Onset }}$ & NODIPH \\
\hline 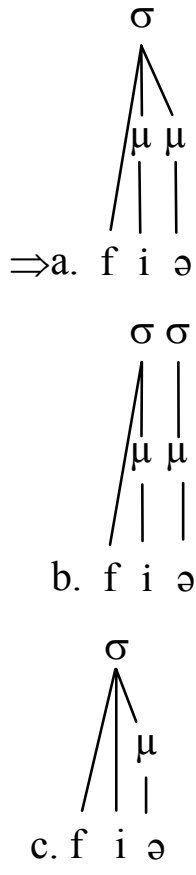 & *! & . & $*$ & $*$ \\
\hline
\end{tabular}

6 I assume that ${ }^{*}$ COMPLEX $_{\text {Onset }}$ is ranked above NODIPH but, as (7) shows, this ranking is not crucial. 
The high-ranked ONSET, requiring that the syllables have onsets, eliminates candidate ( $7 \mathrm{~b})$ from evaluation. Candidate (7c), which has a $\mathrm{Cj} \mathrm{V}$ structure, is ruled out by MAX $\mu$. Additionally, this candidate violates ${ }^{*}$ COMPLEX $_{\text {Ons }}$. The low ranking of NODIPH ensures that the candidate having a diphthong on the surface wins (7a).

As demonstrated in Rubach (2000), the insertion of the glide in the Polish word trio is due to the following ranking of constraints: IDENT $\sigma$, ONSET $>>$ DEPSeg $>>*^{*}$ COMPLEX $_{\text {Ons }}$, MAX $_{\mu}$, where IDENT $\sigma$ mandates that the syllable node on the input must be preserved on the correspondent of that segment in the output and $\mathrm{DEP}_{\text {Seg }}$ prohibits an insertion of a segment. Let us see how the constraints interact with each other to generate the erroneous [fijes] from fierce [fros]. Notice that the English /ra/ has been restructured as the underlying //I $/ /$ in Polish. Moreover, $i$ is prespecified for a syllable node. The evaluation is shown in (8).

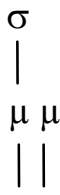

8) //f i $\varepsilon / /$ fierce [fio]

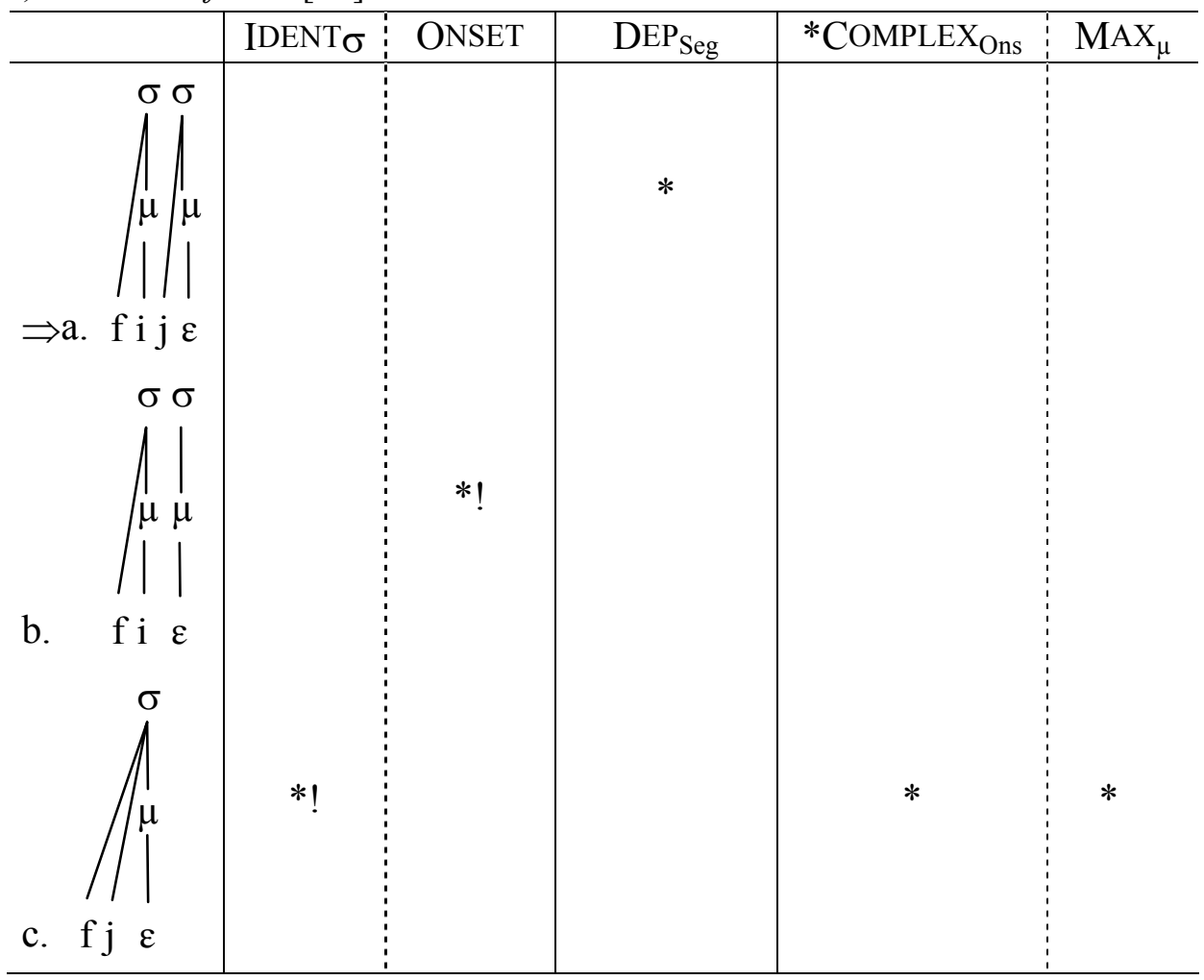


The insertion of the back glide [w] in poor [uwe] seems to parallel the process of insertion in words such as aktualny 'current'. However, the analysis developed so far cannot generate the correct output for words such as poor [uwe]. This problem can be solved by introducing two levels of evaluation (Kiparsky 1997, 2000; Rubach 1997, 2000, 2003). At Level 1, gliding has to be banned and this is achieved by the following ranking: Level 1: *ONSET [w] >> ONSET $>\mathrm{DEP}_{\text {Seg, }}$, where $*$ ONSET $[\mathrm{w}]$ prohibits the glide [w] in the onset. At Level 2, the $/ / \mathrm{u} / /$ is specified for the syllable node. IDENT $\sigma$ ensures that $u$ does not lose its syllabic specification, while the high-ranked ONSET forces [w] insertion. The ranking at Level 2 is as follows: IDENT $\sigma_{\sigma}$, ONSET $>>*$ ONSET $[w]>>D^{2} P_{\text {Seg. }}$. The tableaux in (9i-ii) show the evaluation of poor [puwe], where the glide is predicted to appear as a consequence of interference.

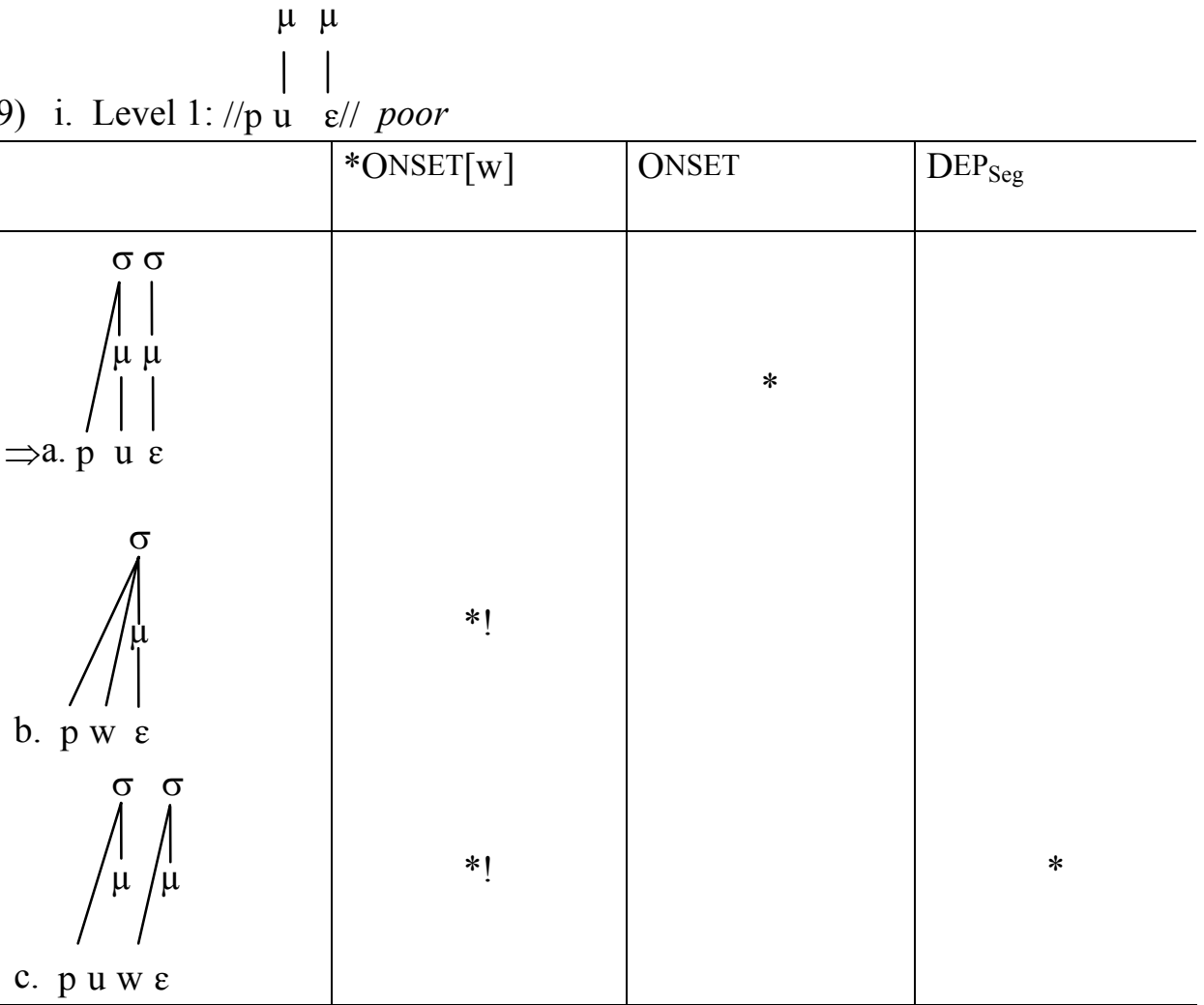




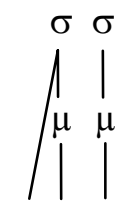

ii. Level 2: /p u $\varepsilon /$ poor

\begin{tabular}{|c|c|c|c|c|}
\hline & IDENT $\sigma$ & ONSET & *ONSET & $\mathrm{DEP}_{\mathrm{Seg}}$ \\
\hline 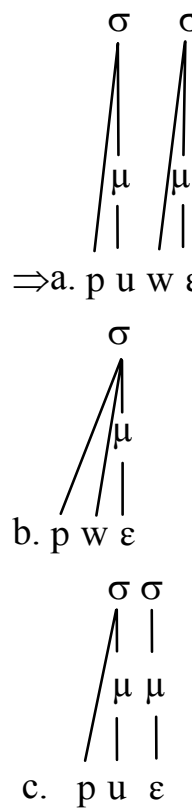 & $* !$ & $* !$ & . & $*$ \\
\hline
\end{tabular}

Let us now return to fierce and poor and explain the problem of the lack of gliding in the outputs exhibited by learners. Following Rubach (2000), Polish has the gliding of $i$ but not of $u$ in the prevocalic context. This fact plays a role in generating [fijes] and [puwe] instead of [fjes] and [pwe]. In the case of poor, the answer seems to be clear. Namely, such an error would require $u$-Gliding in the prevocalic context, but such gliding does not exist. The absence of [fjes] requires an explanation. In $i \mathrm{~V}$ strings, Polish and English have gliding, for ex-

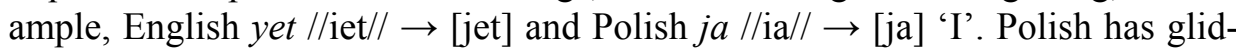
ing also in $\mathrm{C} i \mathrm{~V}$ strings and gliding in such strings distinguishes Polish from other languages, for example, biolog //bı// $\rightarrow$ bjo] 'biologist' in Polish but $/ / \mathrm{bIo} / / \rightarrow[\mathrm{b} ı$ o in Slovak. Moreover, Polish uses prespecification in $\mathrm{CiV}$ strings, which results in the lack of gliding and the application of glide insertion. This happens in some recent borrowings. However, this scenario may not always be true. For instance, it seems that the English word idiom is mispronounced more 
often as [idjom] than as [idijom], so gliding and not glide insertion applies. Therefore, it looks like both strategies are used by English-speaking Poles.

Returning to English, Wells (2000) points out that sometimes a sequence of two unstressed high vowels has two possible pronunciations: either as two separate syllables, or as a compressed single syllable. This is shown by many English words such as lenient and idiom which have a slower pronunciation variant with [ı], i.e. [li..nıənt], and a faster one with [jə], i.e. [li..njənt]. Wells also admits the two variants of pronunciation in words containing a weak vowel $u$, as in influence, which can be pronounced either with [ひə] or with [wə]. This observation also finds support in Jones (1956), who remarks that the centring diphthongs /Iə/ and / $\mathrm{v} /$ differ from the closing ones because the second element is actually fully articulated in the former and in some contexts it is longer than normally, e.g. in influence. It has to be stressed, however, that not every diphthong and in every position of the word may show such a variation. The issue is much more complex than presented in this article and requires further research. One possible account for such variations in pronunciation is suggested below.

In OT, variations in pronunciation result from the lack of ranking between constraints (Prince - Smolensky 1993; McCarthy - Prince 1993, 1994, 1995).

Obviously, $i$ that loses its underlying mora is syllabified into the syllable onset, creating a complex onset. Complex onsets, in turn, are more marked in comparison to simple onsets. In OT, this marking is expressed by * COMPLEX $_{\text {Onset, }}$ a constraint penalizing complex onsets. As shown by the variant pronunciation of lenient [li.njent], complex onsets occur in English. This means that the constraint is violable. However, the occurrence of complex onsets in English is not restricted to the above given examples. The evidence for complex onsets is provided by other words such as play, cry and stay. Furthermore, there is a number of words, such as queue [kju:], few [fju:], view [vju:], or tune [tju:n], where the front glide [j] appears after noncoronal consonants and before [u:].

In Generative Phonology, the glide [j] derives from the underlying //i//. In words such as queue, few, view, tune, the glide [j] is integrated into the onset. Therefore, it can be assumed that lenient and queue are similar with respect to the syllable structure if lenient is pronounced with a glide, i.e. the syllable constitutes a CCV string: [lii.njent] and [kju:]. The form [linnont] is obtained by ranking NODIPH below $\mathrm{MAX}_{\mu}$ and ONSET. This is illustrated in (10). 


\begin{tabular}{|c|c|c|c|c|}
\hline & ONSET & $\mathrm{MAX}_{\mu}$ & *COMPLEX ${ }_{\text {Onset }}$ & NODIPH \\
\hline 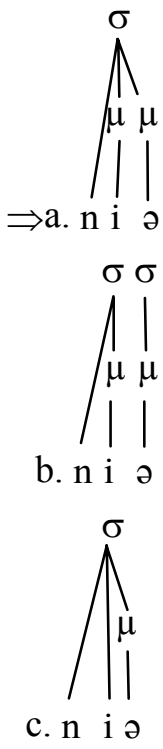 & $* !$ & $* !$ & * & * \\
\hline
\end{tabular}

Candidate (10a) comes out as optimal as its contenders violate the high-ranked ONSET (10b) and $\operatorname{MAX}_{\mu}(10 \mathrm{c})$.

As shown in (10), $\mathrm{Cj}$ onsets are not admitted if NODIPH is ranked below ${ }^{*}$ COMPLEX $_{\text {Onset. }}$ Therefore, to obtain [njo] in lenient on the surface, the ranking must be as in (11). 
$\mu \mu$

$1 \mid$

11) //n i ə// lenient [njə]

\begin{tabular}{|c|c|c|c|c|}
\hline & ONSET & NODIPH & *COMPLEX ${ }_{\text {Onset }}$ & $\mathrm{MAX}_{\mu}$ \\
\hline 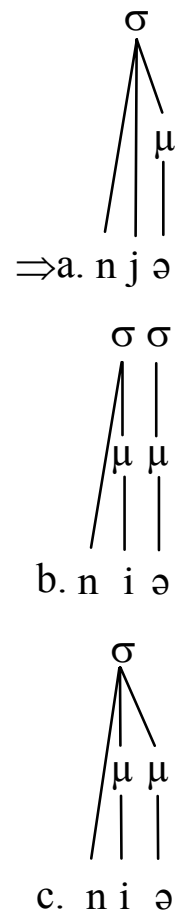 & *! & 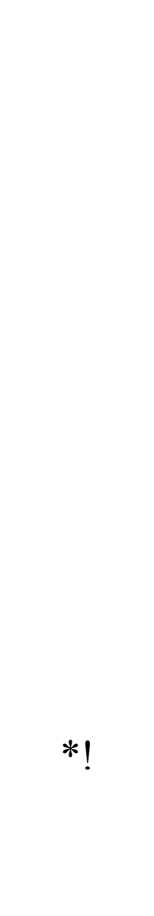 & $*$ & $*$ \\
\hline
\end{tabular}

The high ranking of ONSET ensures that the candidate with no onset (11b) is excluded from evaluation. NODIPH is ranked higher than ${ }^{*}$ COMPLEX Onset $_{\text {and }}$ $\mathrm{MAX}_{\mu}$, which means that it is less costly to create a complex onset than to create a diphthong. Thus, candidate (11a), with a Cj string, comes out as optimal in this evaluation.

To conclude, some words in English, such as lenient, show variation between [CIə] and [Cjə]. This variation can be expressed in OT as a difference in constraint ranking with two different rankings being permissible. The variant containing [Cjə] strings may, next to [Cije], occur in the speech of Polish learners of English and it is then represented as [CjE], a configuration that is desirable given the constraint ranking shown in (11). 


\section{Summary}

This paper has discussed the process of gliding in relation to the interference that appears in the pronunciation of Polish learners of English. It has been argued that the relevant mispronunciations stem from the transfer of phonological rules active in the native language or from the differences in phonological systems. On the one hand, it has been demonstrated that the errors made in the closing diphthongs are due to the difference in the phonological representation of VV sequences in Polish and English. On the other hand, it has been shown that the errors made in the English centring diphthongs are a straightforward effect of glide insertion in $i \mathrm{~V}$ strings. It has also been shown that while Standard OT can generate $j$-Insertion in words such as fierce, $w$-Insertion in influence or poor requires an introduction of a two-level evaluation and, in consequence, the modification of standard OT.

\section{REFERENCES}

Beckman, Jill N. - Laura Walsh Dickey - Suzanne Urbanczyk (eds.)

1995 Papers in Optimality Theory. (University of Massachusetts Occasional Papers in Linguistics 18.) Amherst: University of Massachusetts, GLSA.

Booij, Geert E. - Jaap van Marle (eds.)

1994 Yearbook of morphology 1993. Dordrecht: Kluwer.

Casali, Roderic F.

1996 Resolving hiatus. [Unpublished Ph.D. dissertation, University of California].

1997 “Vowel elision in hiatus contexts: Which vowel goes?", Language 73: 493-533.

Chomsky, Noam - Morris Halle

1968 The sound pattern of English. New York: Harper \& Row.

Dziczek-Karlikowska, Hanna

2007 Error-based evidence for the phonology of glides and nasals in Polish with reference to English. [Unpublished Ph.D. dissertation, University of Warsaw].

Gimson, Alfred C.

2001 Introduction to the pronunciation of English. London: Arnold.

Goldsmith, John A.

1986 The handbook of phonological theory. Oxford: Oxford University Press.

Hayes, Bruce

1989 “Compensatory lengthening in moraic phonology", Linguistic Inquiry 20: 253-305.

Hock, Hans

1986 "Compensatory lengthening: In defence of the concept 'Mora"”, Folia Linguistica 20: 431-460.

Jassem, Wiktor

1971 Podręcznik wymowy angielskiej. [Handbook of English pronunciation]. Warszawa: Państwowe Wydawnictwo Naukowe. 
Jones, Daniel

1956 The pronunciation of English. ( $4^{\text {th }}$ edition). Cambridge: Cambridge University Press.

Kiparsky, Paul

1997 LP and OT. [Handout, LSA Summer Linguistic Institute, Cornell University, Ithaca, N.Y.].

2000 "Opacity and cyclicity", The Linguistic Review 17: 351-367.

Ladefoged, Peter

1993 A course in phonetics. Fort Worth: Harcourt Brace College Publishers.

McCarthy, John J. - Alan S. Prince

1986 "Prosodic morphology", in: John A. Goldsmith (ed.), 318-366.

1993 Prosodic morphology I: Constraint interaction and satisfaction, available at: http://scholarworks.umass.edu/cgi/viewcontent.cgi?article=1013\&context=linguist_fa culty pubs (date of access: October 2010).

1994 "Generalized alignment", in: Geert E. Booij - Jaap van Marle (eds.) Yearbook of morphology 1993, 79-153.

1995 "Faithfulness and reduplicative identity", in: Jill N. Beckman et al. (eds.) Papers in optimality theory, 249-384.

Prince, Alan - Paul Smolensky

1993 Optimality theory: Constraint interaction in generative grammar, available at: http://roa.rutgers.edu/files/537-0802/537-0802-PRINCE-0-0.PDF (date of access: October 2010).

Reszkiewicz, Alfred

1984 Correct your English pronunciation. Warszawa: Państwowe Wydawnictwo Naukowe.

Roca, Iggy (ed.)

1997 Derivations and constraints in phonology. Oxford: Oxford University Press.

Rosenthall, Samuel

1994 Vowel/glide alternation in a theory of constraint satisfaction. [Unpublished Ph.D. dissertation, University of Massachusetts, Amherst].

Rubach, Jerzy

1997 "Extrasyllabic consonants in Polish: Derivational optimality theory", in: Iggy Roca (ed.) Derivations and constrains in phonology, 551-581.

1984 Cyclic and lexical phonology. The structure of Polish. Dordrecht: Foris.

2000 "Glide and glottal stop insertion in Slavic languages: A DOT analysis", Linguistic Inquiry 31: 271-317.

2003 "Polish palatalization in derivational optimality theory", Lingua 113: 197-237.

Sobkowiak, Włodzimierz

2001 English phonetics for Poles. Poznań: Wydawnictwo Poznańskie. Wells, John C.

2000 Longman pronunciation dictionary. Harlow: Pearson Education. 